\title{
Tissue Distribution and Regulation of the Small Sar1b GTPase in Mice
}

\author{
Valérie Marcila,b Ernest Seidman ${ }^{\mathrm{a}} \quad$ Daniel Sinnett $^{\mathrm{b}, \mathrm{d}} \quad$ Rocio Sanchez ${ }^{\mathrm{b}}$ \\ Schohraya Spahis ${ }^{b, c}$ Alain Sanéb Emile Levy ${ }^{b, c}$
}

${ }^{a}$ Research Institute, McGill University, Campus MGH, C10.148.6, Montreal, ${ }^{b}$ Research Centre, CHUSainte-Justine, Departments of ${ }^{c}$ Nutrition and dPediatrics, Université de Montréal, Montreal, Quebec, Canada

\author{
Key Words \\ Sar1b GTPase • Transgenic mice • Coat protein complex II vesicles • Gene expression
}

\begin{abstract}
Background/Aims: Sar1b GTPase (Sar1b) represents an obligatory component of COPII vesicles that bud from the endoplasmic reticulum to transport proteins to the Golgi apparatus. Its genetic mutations lead to a severe disorder known as chylomicron retention disease. Despite growing knowledge on Sarlb, little is known about it tissue distribution and regulation, which constitute the aims of the present study. We aimed to determine the Sar1b tissue distribution and modulation by a high-fat diet and gene forcing using transgenic mice in comparison to wild-type mice. Methods: The expression pattern of Sar1b was studied in different organs of wild-type and Sar1b transgenic mice by qRT-PCR and Western blot. The effect of transgenesis and insulin resistance induced by a 12-week high-fat diet on Sar1b gene expression was also assessed by qRT-PCR. Results: Evaluation of Sar1b mRNA revealed the skeletal muscle as the tissue with the highest Sar1b expression, followed by the heart and liver, the organs composing the digestive tract, the brain and finally the lung and the adipose tissue. Sar1b protein expression levels follow a similar pattern among the organs, except for its lower expression in the heart. While the high-fat diet did not exert any significant alterations, Sar1b transgenic mice displayed higher gene expression in the liver, ileum, jejunum, proximal and distal colon compared to wild-type mice. Conclusion: Our study supports the importance of Sar1b in organs involved in lipid transport and/or calcium trafficking such as the liver, intestine, skeletal muscle and heart.
\end{abstract}




\section{Introduction}

In eukaryote cells, intracellular delivery to downstream compartments requires that newly synthesized and properly folded proteins are transported from the endoplasmic reticulum (ER) to the Golgi network via coat protein complex (COP) II vesicles [1-3]. As revealed by numerous studies [4], COPII polymerizes on the membrane surface, captures cargo and SNARE molecules, and deforms the membrane to sculpt out vesicles [5]. Importantly, COPII vesicle biogenesis is initiated by the activation of a small Sar1 GTPbinding protein through Sec12, a guanine nucleotide exchange factor [6, 7]. The presence of Sar1b-GTPase (Sar1b) stimulates the recruitment of the inner coat components Sec23 and Sec24, which are responsible for capturing cargo proteins into the nascent vesicles [8, 9]. Then, the Sec13/31 heterotetramer is recruited to form the outer coat and stabilize the cargo-bound pre-budding complexes $[3,7,10]$.

The Sar1 protein has two paralogs, Sar1a and Sar1b. In humans, the SAR1B gene (SARA2, HGNC: 10535; MIM *607690), not SAR1A, was identified as the specific gene undergoing molecular defects present in Anderson's disease or chylomicron (CM) retention disease, a rare autosomal recessive disorder characterized by an inability of the enterocytes to export dietary lipids via CMs. To date, 16 SAR1B mutations have been described in patients with CM retention disease [11-19]. No mutation in the $S A R 1 A$ gene has been detected in patients with this specific disease. Accordingly, it has been suggested that, in enterocytes, the Sar1b paralogue would be used specifically for pre-CM mobilization by transport vesicles while the Sar1a paralogue would be employed for the transport of small soluble and membrane bound proteins by transport vesicles [15].

Patients with CM retention disease present with steatorrhea, chronic diarrhea and failure to thrive, as well as low plasma lipid and liposoluble vitamin levels, causing neurological impairment [20-23]. It appears that Sar1b is involved in multiple aspects of the cargo sorting process, e.g. the regulation of COPII coat dynamics and membrane deformation during vesicle formation, which dictates routing of numerous proteins and triglyceriderich lipoproteins, including $\mathrm{CM}$ in the small intestine and very-low-density lipoproteins in the liver [11, 24]. Additional convincing evidence has recently been obtained by genetic manipulation; our previous study clearly demonstrated that Sar1b overexpression mediates stimulation of intestinal lipid transport, which was likely induced by the efficient assembly of CMs [25].

Despite the importance of Sar1b in COPII vesicle elaboration, there is an important gap of knowledge on the status and regulation of Sar1b in different organs. In this study, we assessed the tissue distribution and regulation by a high-fat diet and gene forcing of Sar1b gene expression in wild-type (WT) and transgenic (TG, Sar1 $\mathrm{b}^{+/+}$) mice.

\section{Materials and Methods}

\section{Generation of Sar1b transgenic mice}

The pCMV6-XL4 vector (OriGene Technologies, Rockville, MD), harbouring full length cDNA of SAR1B, was digested with NotI to excise a 1960 bp fragment. This fragment was subsequently cloned into a pBROAD3-mcs vector (InvivoGen, San Diego, CA) restricted with NotI to create pBROAD3-SAR1B. pBROAD3 features the ubiquitous mouse ROSA26 promoter, a high CpG content promoter that directs in vivo expression of the transgene [26]. Chicken $\beta$-globin gene insulator was subcloned upstream the ROSA26 promoter at the $N d e$ I site to enhance transgene expression. Cloning of the $\beta$-globin gene insulator created pBROAD3- $\beta$-SAR1B vector. This $2 \mathrm{~kb}$ insulator fragment was derived from PCR amplification of chicken DNA with insulator specific primers containing NdeI site (primer 1: CATATGGCGGCCGCTCTAGACT; primer 2: CATATGGGATCCGTCGACGC). The capability of this construct to allow SAR1B expression in enterocytes was tested by transient transfection of Caco- $2 / 15$ cells. The DNA transgene vector, pBROAD- $\beta$-SAR1B, was then injected in fertilized eggs from 129/Sv mice at the Réseau de Recherche en Transgenèse du Québec facility. 
Genomic DNA was prepared from founder mice and their offspring tail, and screened for the presence of SAR1B DNA by PCR amplification, using specific primers (primer 1: ATGTCCTTCATATTTGGATT; primer 2: ATCAATGTACTGTGCCATCC). Experiments were performed in male mice of mixed 129/Sv x C57BL6 backgrounds.

\section{Animals and diets}

Three-week-old TG for Sar1b and WT mice were housed in a temperature-controlled room at $24^{\circ} \mathrm{C}$ with a 12-h light-dark cycle and maintained on a standard laboratory chow normal diet (2018 Teklad Global 18\% protein rodent diet, Harlan Laboratories, Indianapolis, IN) or a high-fat diet (BioServ F3282 $60 \%$ fat Calories, BioServ, Frenchtown, NJ) and double distilled water ad libitum for 12 weeks. Animal experiments were conducted according to the Canadian Council on Animal Care guidelines for the care and use of experimental animals and were approved by the institutional animal care committee of Sainte-Justine Research Center.

\section{Biochemical Analyses}

After 12 weeks of feeding, mice were fasted overnight, weighed and sacrificed. Blood was collected for insulin and lipid assays. Plasma triglycerides and cholesterol levels were measured enzymatically (Boehringer-Mannheim, Mannheim, Germany). Blood glucose levels were determined using a OneTouch Ultra Meter (LifeScan, Milpitas, CA) and plasma insulin was measured using a rat/mouse insulin ELISA kit (Millipore, Billerica, MA). Plasma fatty acid composition was determined by gas chromatography as described previously [25]. Insulin sensitivity was determined using the HOMA-IR index. The score was calculated using the formula: (Insulinemia (mIU/L) x Glycemia (mmol/L)) / 22.5.

\section{Cell Culture for Antibody Specificity}

To test the specificity of our Sar1a/b antibody, we cultured Caco-2/15 cells for 14 days postconfluence as previously described [27]. We also established Caco-2/15 cell line overexpressing Sar1b and green fluorescent protein (GFP). To do so, the blunt-end PCR fragment encoding SAR1B gene was amplified from the human cDNA clone SC114457 (Origene Technologies, Rockville, MD) with ATGTCCTTCATATTTG as forward primer and CAGATCCTCTTCTGAGATGAGTTTTTGTTCATCAATGTTACTGTGCCAT containing myc epitope as reverse primer and TOPO Cloned into pLenti6/V5-D-TOPO (Invitrogen Corp., Carlsbad, CA 92008) to create an expression construct. The pLenti6/V5-D-TOPO expression plasmid of SAR1B was then transfected into Caco-2/15 cells with GenJet In Vitro Transfection Reagent (SignaGen Laboratories, Ijamsville, MD) according to the supplier's instructions. Generation of stable cell line was achieved using Blasticidin selection at a concentration of $1 \mu \mathrm{g} / \mathrm{mL}$. Control Mock cells were obtained by transfection with pLentiV5/GFPtag (kindly provided by Dr. Jean-François Beaulieu, Université de Sherbrooke, Sherbrooke, Canada) harbouring the same features as the pLenti6/V5-D-TOPO system.

\section{Western Blot Analysis}

Sections of different organs from a total of 12 mice ( 3 mice/group for the 4 groups: WT-normal diet; WT-high-fat diet; TG-normal diet; TG-high-fat diet) were homogenized in ice-cold T-PER Tissue Protein Extraction Reagent (Thermo Scientific, Rockford, IL). Protease inhibitors were added to tissues prior to homogenization. As for Caco-2/15 cells, they were homogenized and adequately prepared for Western blotting as described previously [27]. The Bradford assay was used to estimate protein concentration. Supernatant proteins $(20 \mu \mathrm{g})$ were denatured at $95^{\circ} \mathrm{C}$ for $5 \mathrm{~min}$ in a sample buffer containing sodium dodecyl sulfate (SDS) and dithiothreitol (Thermo Scientific, Rockford, IL), separated on a 15\% SDS-polyacrylamide gel electropheresis (SDS-PAGE) and electroblotted onto Hybond-C extra nitrocellulose membranes (Amersham Biosciences, Piscataway, NJ) in $25 \mathrm{mM}$ Tris and $192 \mathrm{mM}$ glycine. Nonspecific binding sites of the membranes were blocked with Tris-buffered saline [20 mM Tris- $\mathrm{HCl}(\mathrm{pH} 7.5)$ plus $137 \mathrm{mM} \mathrm{NaCl}]$ containing $0.1 \%$ Tween 20 and $5 \%$ non fat dry milk for $60 \mathrm{~min}$ at room temperature. The blots were then incubated overnight at $4{ }^{\circ} \mathrm{C}$ in blocking solution with the primary antibodies directed against the targeted proteins Sar1b/a $(1: 20,000)$ (kindly provided by Dr Randy Schekman, Department of Molecular and Cell Biology, University of California at Berkeley, Berkeley, CA), $\beta$-actin 1:250,000 (Sigma Aldrich) and myc (1:250) (provided by Dr Mounib Elchebly, Sainte-Justine Hospital Research Center, Montreal, Canada). The relative amount of primary 
antibody was revealed with a species-specific horseradish peroxidase-conjugated secondary antibody, e.g. anti-mouse IgG-POD/anti-rabbit IgG-POD $(1: 20,000)$ (Roche Diagnostics, Indianapolis). Blots were developed and the protein mass was quantified using an HP Scanjet scanner equipped with a transparency adapter and the UN-SCAN-IT gel 6.1 software.

\section{RNA Extraction and Reverse Transcription}

Tissue specimens obtained from a total of 24 mice $(6$ mice/group for the 4 groups: WT-normal diet; WT-high-fat diet; TG-normal diet; TG-high-fat diet) were immediately conserved in RNA-Later according to the manufacturer's protocol. They were homogenized in TRIzol reagent (Ambion by Life Technologies Corporation, Carlsbad, CA) and total RNA was extracted. RNA concentration and quality were tested by absorbance at $260 \mathrm{~nm}$ while the absorbance ratio of 260/280 (using a Nanodrop® ND1000 Spectrophotometer from Thermo Scientific, Wilmington, DE) and RNA analysis by agarose gel electrophoresis served to assess integrity. Complementary DNA was obtained by reverse transcripting $1 \mu \mathrm{g}$ of RNA with the qScript cNDA Supermix (Quanta Biosciences, Gaithersburg, MD) according to the manufacturer's instructions. Negative controls without enzyme were also prepared.

\section{Quantitative PCR}

The TaqMan ${ }^{\circledR}$ Express Human Endogenous Control Plate (Applied Biosystems, Foster City, CA) was used to select the most stable reference gene amongst organs according to the manufacturer's instructions. Using this technique, polymerase (RNA) II (DNA directed) polypeptide AI (Polr2a) was chosen as an endogenous control to normalize the different cDNA sample amounts. Quantitative PCRs (qPCR) were performed in 96-wells microtiter plates using Taqman ${ }^{\circledR}$ Fast Advanced Master Mix (Applied Biosystems) in an Applied Biosystems Step One Plus ${ }^{\mathrm{TM}}$ Real-Time PCR System (Applied Biosystems). The qPCRs were carried in 96-well plates with a final volume of $10 \mu \mathrm{l}$ per well. A volume of $5 \mu \mathrm{l} \mathrm{Taqman}{ }^{\circledR}$ Fast Advanced Master Mix $(1 \mathrm{X})$ was added to a well containing $1 \mu \mathrm{l}$ of Custom Taqman ${ }^{\circledR}$ Gene Expression Assay (Applied Biosystems) $(1 \mathrm{X})$ for Sar $1 b$ or for Polr2a comprising $1 \mu \mathrm{l}$ of cDNA previously diluted 1:5 and $3 \mu \mathrm{l}$ of diethylpyrocarbonate $\mathrm{H}_{2} \mathrm{O}$. Taqman ${ }^{\circledR}$ hydrolysis probes used were Mm01294633_m1 for Sar1b and Mn00839493_m1 for Polr2a (Applied Biosystems). Subsequently, negative controls without cDNA were prepared. The amplification reaction was carried out using 40 cycles and was performed in duplicate for each gene in the same plate under the following conditions: $95^{\circ} \mathrm{C} 20 \mathrm{~s}, 95^{\circ} \mathrm{C} 1 \mathrm{~s}$ and $60^{\circ} \mathrm{C}$ for $20 \mathrm{~s}$.

\section{Analyses}

The relative mRNA fold-changes (relative quantification) between the animal groups were calculated using the $2^{-\Delta \Delta C t}$ method [28]. For each sample, the first $\Delta \mathrm{Ct}$ was calculated using the corresponding endogenous control. The second $\Delta \mathrm{Ct}$ was calculated using the defined control group. For the comparison of Sar1b gene expression in the different organs, the average $\Delta \mathrm{Ct}$ of the lung group was used as reference. Similarly, the average $\Delta \mathrm{Ct}$ was employed for the comparison of Sar $1 \mathrm{~b}$ gene expression between WT and TG mice under the normal chow and high-fat diets, using the WT/normal diet mice as reference. Exponential values were then transformed in linear values and expressed as relative fold change in gene expression. The analyses and statistics were performed using the Expression Suite Software Version 1.0 (Applied Biosystems) and the Prism 5 for Mac Software Version 5.0d (GraphPad Software Inc., La Jolla, CA). Data are expressed as means \pm SEM. For statistical analysis, one-way ANOVA followed by Bonferroni's multiple comparison test or t-tests were used and a $P$ value $<0.05$ was considered significant.

\section{Results and Discussion}

At first, we characterized the metabolic and lipid profile of mice from each group at sacrifice, following a 12-week diet. Results are presented in Table 1. To determine whether the overexpression of Sar1b influenced diet-induced obesity, male TG mice were maintained with ad libitum access to a pelleted high-fat diet. Then anthropometric and biochemical parameters were assessed. Although high-fat diet increased body weight in TG and WT mice, the mean body weight of TG carriers was slightly higher compared to corresponding WT controls. Similarly, the high-fat diet led to a rise in glucose and insulin in WT and TG mice, 
Table 1. Metabolic characteristics of mice at sacrifice. Mice were sacrificed after being fed a normal or highfat diet for 12 weeks. Results represent the means \pm SEM of 6 animals per group. One-way ANOVA were performed $(\mathrm{P}<0.0001)$ followed by Tuckey's multiple comparison tests. ${ }^{*} \mathrm{P}<0.05 ;{ }^{* *} \mathrm{P}<0.01$; ${ }^{* * *} \mathrm{P}<0.001$ vs. Wild-type, normal diet mice. ${ }^{\#} \mathrm{P}<0.05$; ${ }^{\# \#} \mathrm{P}<0.01$; ${ }^{\# \#} \mathrm{P}<0.001$ vs. Transgenic, normal diet mice

\begin{tabular}{lcccc}
\hline & $\begin{array}{c}\text { Wild-type } \\
\text { Normal Diet }\end{array}$ & $\begin{array}{c}\text { Wild-type } \\
\text { High-fat Diet }\end{array}$ & $\begin{array}{c}\text { Transgenic } \\
\text { Normal Diet }\end{array}$ & $\begin{array}{c}\text { Transgenic } \\
\text { High-fat Diet }\end{array}$ \\
\hline Weight (g) & $29.35 \pm 2.14$ & $34.90 \pm 2.13$ & $37.67 \pm 2.74^{*}$ & $50.70 \pm 0.72^{* * *, \# \#}$ \\
Blood glucose (mmol/L) & $6.00 \pm 0.20$ & $6.70 \pm 0.20$ & $7.00 \pm 0.20^{* *}$ & $7.80 \pm 0.10^{* * *, \# \#}$ \\
Insulin (ng/mL) & $0.71 \pm 0.06$ & $1.20 \pm 0.08^{* *}$ & $1.60 \pm 0.12^{* * *}$ & $2.41 \pm 0.17^{* * *, \# \#}$ \\
HOMA-IR (mIU/L*mmol/L)/22.5 & $5.00 \pm 0.60$ & $9.30 \pm 0.60$ & $13.00 \pm 1.10^{* * *}$ & $22.40 \pm 1.60^{* * *, \# \#}$ \\
Triglycerides (mmol/L) & $0.68 \pm 0.07$ & $1.23 \pm 0.12^{* *}$ & $1.00 \pm 0.09$ & $1.50 \pm 0.13^{\# \#}$ \\
Total cholesterol (mmol/L) & $3.80 \pm 0.40$ & $4.70 \pm 0.50$ & $5.20 \pm 0.50$ & $5.90 \pm 0.50^{*}$ \\
\hline
\end{tabular}

Fig. 1. Protein expression Sar1 in Caco-2/15 cells. (A) Proteins from cell homogenates were extracted and protein expression was measured by Western blot as described in the Material and Methods section. A representative blot is shown. (B) After transfection with GFP and Sar1b constructs, Caco-2/15 cells were allowed to differentiate for 14 days before being tested for Sar1b protein expression by Western blot using anti-Sar1 and anti-myc antibodies. Results represent the means \pm SEM of 3 experiments and were calculated as densitometric ratios of Sar1b/a to Sar1b-myc and are illustrated as $\%$ of Sar1a/b. A representative blot is shown. *** $\mathrm{P}<0.0001$ vs. Sar1a/b.

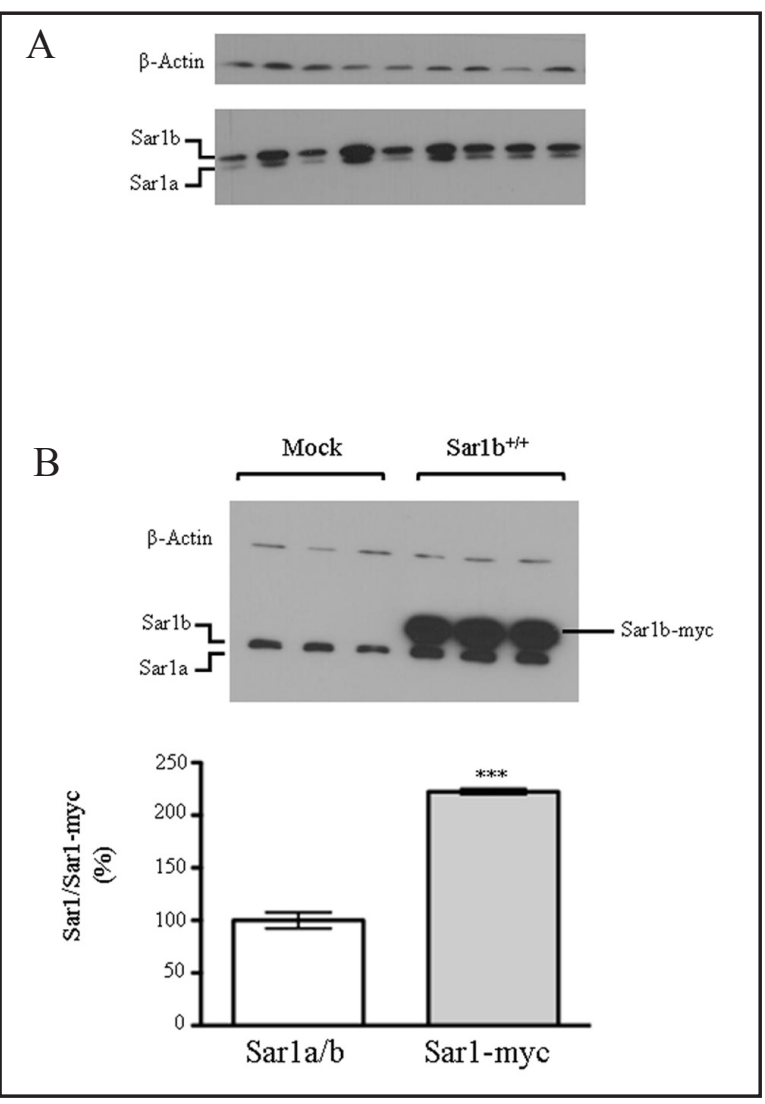

but the increase was more substantial in the Sar1 $\mathrm{b}^{+/+}$mice. Noteworthy, differences in these variables in WT and TG mice were observed even on the regular chow diet, which depicts the separate influence of the two factors, i.e. transgenesis and diet. As a result from the glucose and insulin modifications, the HOMA-IR index showed a more significant increase in the Sar $1 \mathrm{~b}^{+/+}$mice vs. controls, thereby indicating reduced insulin sensitivity. Finally, our data show that the high-fat diet caused an augmentation in plasma triglycerides and cholesterol levels in WT and TG mice, but their increment was more substantial in Sar1 $\mathrm{b}^{+/+}$mice. Hence, as expected, the HFD induced a state of insulin resistance and dyslipidemia in the animals, and these effects were exacerbated by Sar1b transgenesis. A study, recently published by our group, has described the complete metabolic profile of Sar1 $\mathrm{b}^{+/+}$mice under control and highfat diets and corroborates the present findings [29]. When fed a HFD, Sar1b ${ }^{+/+}$mice were found to develop obesity, insulin insensitivity, hepatic and plasma lipid abnormalities and CM hyperproduction. This increased triglyceride-rich lipoprotein production elicited by Sar $1 \mathrm{~b}^{+/+}$ mice is in line with our other previous results obtained in Caco-2/15 cells, demonstrating 
Fig. 2. Protein expression Sar1a and Sar1b in transgenic mice. (A) Proteins from liver were extracted and protein expression was measured by Western blot as described in the Material and Methods section. A representative blot is shown. Results represent the means \pm SEM of 3 experiments. Results were calculated as densitometric ratios of Sar1a to Sar1b and are illustrated as \% of Sar1a. A representative blot is shown. ${ }^{* * *} \mathrm{P}<0.0003$ vs. Sar1a.

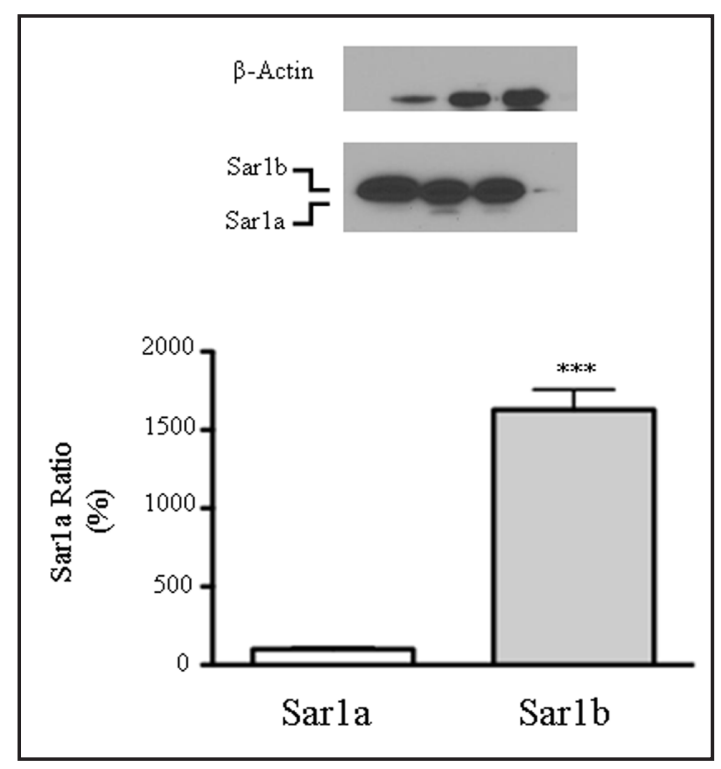

that Sar1b overexpression can enhance intestinal lipoprotein trafficking and sorting [25]. According to the prevailing concept, intestinal CM assembly requires the association of apo B-48 with lipids, which is mediated by microsomal triglyceride transfer protein in the rough ER, resulting in a lipid-poor, small apo B-48-containing particles that serve as precursors of mature CM. The intracellular traffic of apo B-48-containing CM is dependent on the COPII coat complex, which buds vesicles from the ER membrane to transport newly synthesized proteins to the Golgi apparatus. COPII vesicle biogenesis and assembly necessitates Sar1b to trigger a sequence of recruitment events that assemble the COPII coat from its cytosolic components and ultimately drives vesicle budding [2]. Our TG mouse model shows that overexpressing Sar1b leads to increased insulin resistance and dyslipidemia, phenomena that were amplified by the high-fat diet. Although the mechanisms controlling these metabolic changes are still nebulous and deserve further exploration, we propose that the increased intestinal fat absorption associated with Sar1b profusion in Sar1 $\mathrm{b}^{+/+}$mice leads to to greater triglyceride accumulation in the blood circulation and insulin-responsive tissues [29], which would impede glucose uptake and provoke insulin resistance.

We have conducted experiments to determine the specificity of our Sar1b/a antibody in WT and TG animals. First, in Caco-2/15 cells, the Western blots reveal two visible bands, previously described as Sar1b (the upper band) and Sar1a (the lower band) [30] (Fig. 1A). The experiments were repeated in Caco-2/15 cells in which a pLenti6/V5-D-TOPO expression plasmid of $S A R 1 B$ was transfected and, as a result, Sar1b was overexpressed. In this step, not only the blots were incubated with the anti-Sar1b/a antibody, but also with an anti-myc antibody, permitting to distinguish between the endogenous Sar1 and the transfected Sar1b. As illustrated in Fig. 1B, even if the double band (endogenous Sar1a and Sar1b) is still visible, the exogenous form of Sar $1 b$ represented $222 \%$ of the Sar $1 a / b$ band. However, in mice, the band corresponding to the Sar1a protein was barely visible. In fact, the band was rarely observed since Sar1b was overexpressed compared to Sar1a. Fig. 2 shows an experiment where the Sar1a and Sar1b bands could be distinguished in the liver of TG animals. These results showed that the densitometric ratio of Sar1b was over 1,500\% of Sar1a. Hence, we concluded that, although our antibody could recognize Sar1a and Sar1b, the important difference in protein expression, especially in mice, allowed us to study the regulation of Sar1b.

Next, we defined Sar1b protein and mRNA expression in different organs in mice. As shown in Fig. 3A, the organ with the highest mRNA expression of Sar1b was the skeletal muscle, followed by the heart and the liver. The organs composing the digestive system and the brain had similar levels of expression. Finally, we found relatively low gene expression 


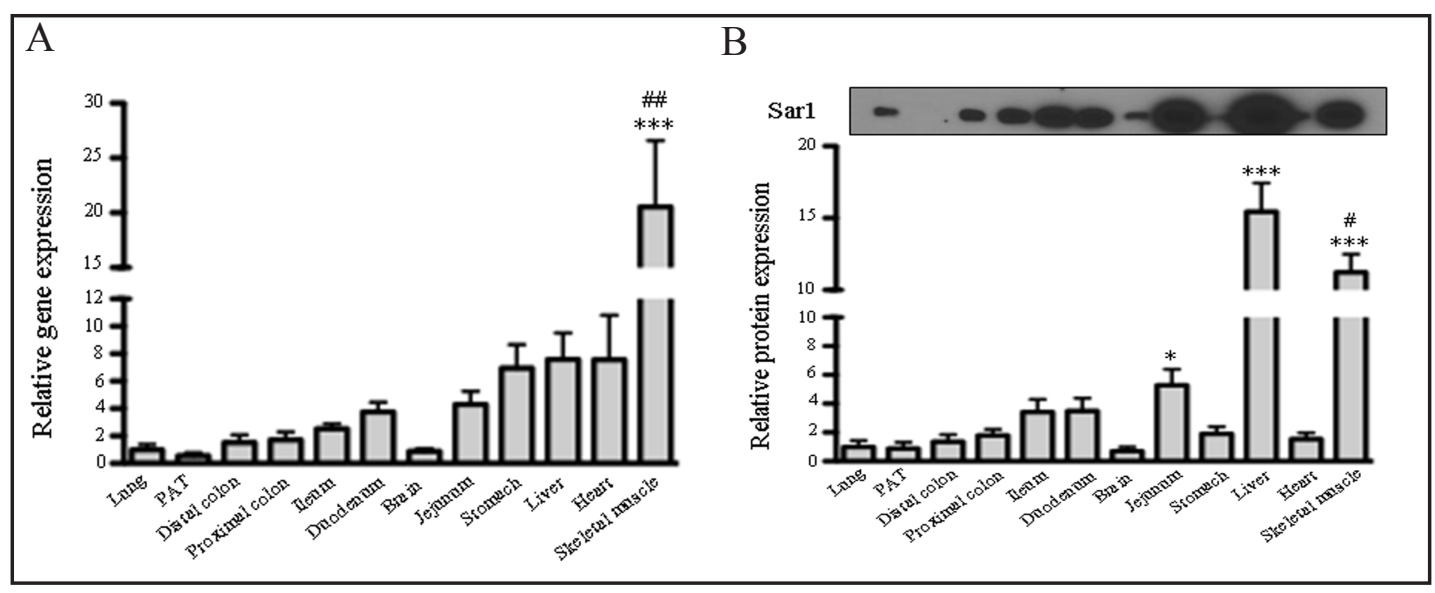

Fig. 3. Differential Sar1b gene and Sar1 protein expression levels in mice organs. RNA (A) and protein (B) from tissues were extracted as described in the Material and Methods section. Gene and protein expression were measured by RT-qPCR and Western blot, respectively. The mean relative expression was calculated relative to lung. Results represent the means \pm SEM of 24 (gene) and 12 (proteins) animals. One-way ANOVA were performed $(\mathrm{P}<0.0001)$ followed by Tuckey's multiple comparison tests. $\mathrm{A}$. ${ }^{* * *} \mathrm{P}<0.001$ vs. lung, $\mathrm{PAT}$, distal colon, proximal colon, ileum, duodenum, brain and jejunum; ${ }^{\#} \mathrm{P}<0.01$ vs. stomach, liver and heart. $\mathrm{B}$. ${ }^{*} \mathrm{P}<0.05$ vs. lung, PAT and brain; ${ }^{* * *} \mathrm{P}<0.001$ vs. lung, PAT, distal colon, proximal colon, ileum, duodenum, brain, jejunum, stomach and heart; ${ }^{*} \mathrm{P}<0.05$ vs. liver. PAT: perirenal adipose tissue. A representative blot is shown.

in the lung and perirenal adipose tissue. The skeletal muscle was the only organ for which post-hoc analyses revealed a significant difference with the others. The measurement of Sar1b at the protein level demonstrated a similar pattern among the organs, except for its lower expression in the heart (Fig. 3B). Western blots showed that the liver was the organ that mostly expressed Sar1b and confirmed the high expression in the skeletal muscle, followed by a roughly equivalent expression in the organs of the digestive tract. The gene and protein expression profile of Sar1b in the duodenum, jejunum and ileum, parts of the digestive system, was relatively equivalent, which corresponds to their respective function in lipid and bile acid handling. It is also important to specify that, since the pattern of Sar1b protein distribution was similar between WT and TG mice under chow and high-fat diet, all the tissue samples from the different groups were analyzed on the same Western blot for comparison needs.

Limited information is available concerning the distribution of Sar1b in various organs despite its crucial function in intracellular trafficking. Using the state-of-the-art technique for mRNA analysis, e.g. qPCR, we documented a preponderance of Sar1b mRNA content in the skeletal muscle. The surprisingly abundant expression of Sar1b in the muscle suggests highly specialized role of Sar1b in this particular tissue, including the regulation of calcium $\left(\mathrm{Ca}^{2+}\right)$ trafficking among multiple $\mathrm{Ca}^{2+}$ storage organelles, for instance the sarcoplasmic reticulum and the ER. In fact, the involvement of Sar1b in $\mathrm{Ca}^{2+}$ trafficking in skeletal muscle was demonstrated a decade ago when calsequestrin, an acidic, low-affinity, high-capacity $\mathrm{Ca}^{2+}$-binding glycoprotein that plays a crucial role in $\mathrm{Ca}^{2+}$ routing to sarcoplasmic reticulum, was found sensitive to the Sar1-H79G mutant, resulting in its accumulation in COPII vesicles in rat skeletal muscle fibers [31]. Later, it was demonstrated that the molecular mechanism underlying the human $\mathrm{Ca}^{2+}$ receptor exit from the ER to the cell surface requires Sar1b and is dependent on COPII vesicles [32]. Likewise, the apoptosis-linked gene 2, a $\mathrm{Ca}^{2+}$-binding protein that serves as a $\mathrm{Ca}^{2+}$ sensor, is dependant of the COPII vesicle formation process and components [33]. Hence, the role of Sar1b in $\mathrm{Ca}^{2+}$ trafficking can explain its high level of expression not only in the skeletal muscle, but also in the heart, in view of $\mathrm{Ca}^{2+}$ signaling and trafficking in cardiomyocytes [34,35]. Accordingly, it was reported that patients with 


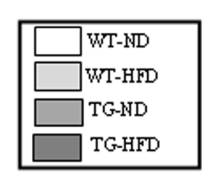

Lung

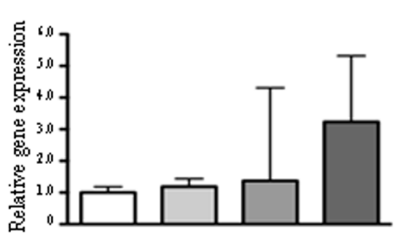

Proximal colon

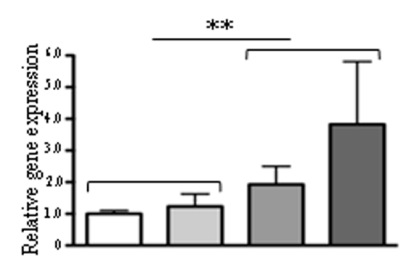

Brain

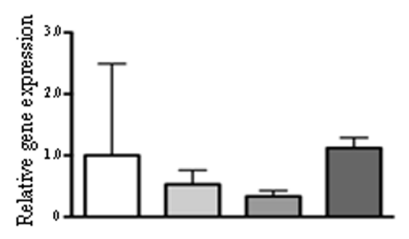

Liver

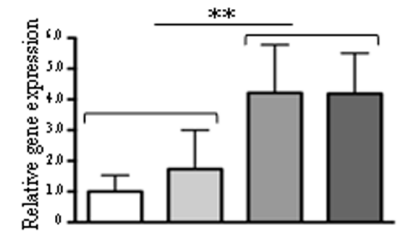

PAT

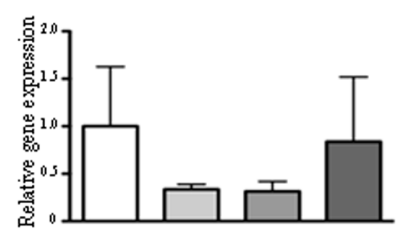

Ileum

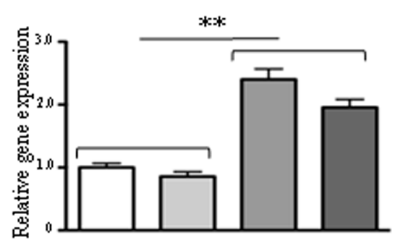

Jejunum

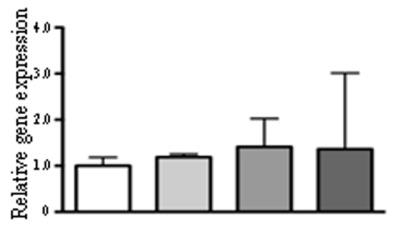

Heart

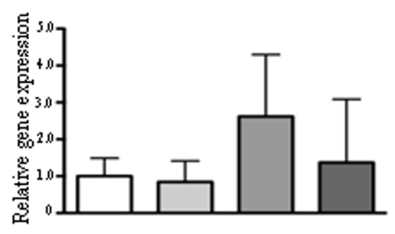

(C) 2014 S. Karger AG, Basel

www.karger.com/cpb

(1)

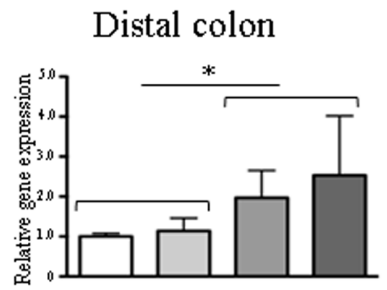

\section{Duodenum}

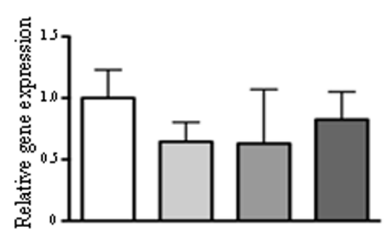

Stomach

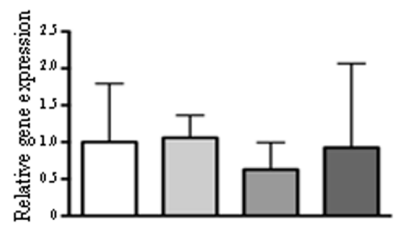

Skeletal muscle

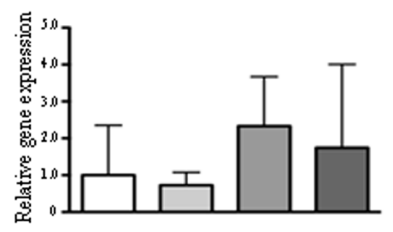

Fig. 4. Effect of diets and transgenesis on the differential gene expression levels of Sar1b in organs in mice. Wild-type and transgenic Sar1b mice were fed a standard laboratory chow or high-fat diet for a 12-week period. RNA from tissues was extracted as described in the Material and Methods section. Gene expression was measured by RT-qPCR and mean relative expression was calculated for each organ to compare gene expression relative to wild-type mice fed a normal diet. Results represent the means \pm SEM of 6 animals per group. T-tests were performed. WT-ND: wild-type mice, normal diet; WT-HFD: Wild-type mice, high-fat diet; TG-ND: Sar1 $\mathrm{b}^{+/+}$transgenic mice, normal diet; TG-HFD: Sar1b ${ }^{+/+}$transgenic mice, high-fat diet; PAT: perirenal adipose tissue. ${ }^{*} \mathrm{P}<0.05$; ${ }^{*} \mathrm{P}<0.01$ vs. wild-type mice; ${ }^{*} \mathrm{P}<0.05$ vs. wild-type/normal diet mice.

chylomicron retention disease suffer from myolysis, cardiac abnormalities and elevated creatine kinase levels [16].

Next, we evaluated the effect of insulino-resistance induced by high-fat diet and the impact of Sar1b transgenesis on Sar1b gene expression in different tissues. The provision of a 12-week high-fat diet to mice did not result in significant changes in mRNA Sar1b 
Fig. 5. Effect of transgenesis on Sar1 protein and Sar1b gene expression in liver and jejunum. Differential levels of Sar1 protein (A) and Sar1b mRNA (B) expression in the liver and the jejunum of wildtype (WT) and transgenic (TG) mice was assessed by Western Blot and by RT-PCR as described in the Material and Methods. A. Results represent the means \pm SEM of 3 animals per group. Results were calculated as densitometric ratios of Sar1b to $\beta$-actin and are illustrated as $\%$ of WT mice. ${ }^{* *} \mathrm{P}<0.004 ;{ }^{*} \mathrm{P}<0.022$ vs. WT mice.

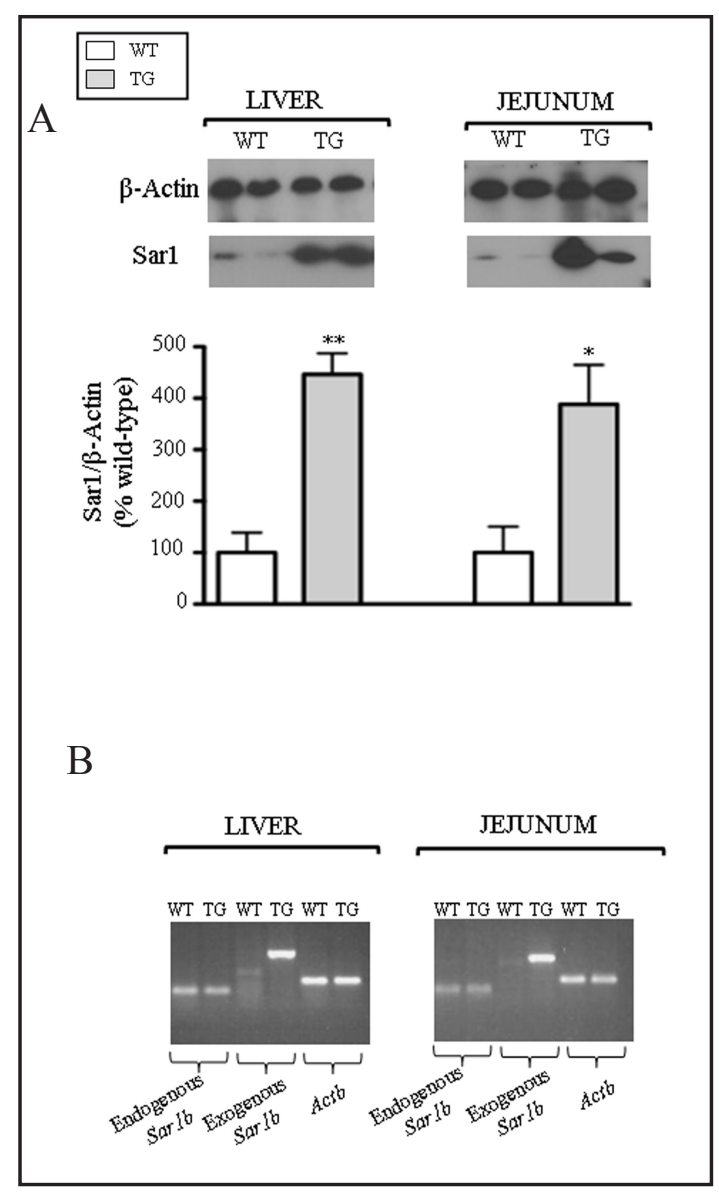

expression in the various tissues when compared to a normal diet in neither WT nor TG mice (Fig. 4). This is divergent from a previous study documenting Sar1b up-regulation by fructose diet and olive oil in Syrian golden hamsters [36], suggesting that the regulation of Sar1b expression by diet and insulin resistance may be species-dependent. Also, in vitro studies have suggested that Sar1b can be regulated by lipids, as demonstrated by the regulation of COPII vesicle formation by lipid composition of membranes [37]. Similarly, depletion of sterols or inhibition of sterol synthesis reduce the mobility of membrane cargo proteins within the ER and inhibit the dynamic interactions of COPII subunits with ER exit sites $[38,39]$. Previous work from our laboratory demonstrated that, in Caco-2/15 cells, Sar1b overexpression promotes intestinal lipid transport in a process involving the COPII network [25]. In the present experimental conditions, the high-fat diet did not effectively regulate $S a r 1 b$ expression, which allows us to speculate that diet could regulate Sar1b turnover without altering mRNA, thereby increasing recycling activity of COPII vesicle.

Our results also revealed that TG mice displayed enhanced mRNA level of Sar $1 b$ in several organs (Fig. 4). Significant enrichment was noted in the liver, ileum, jejunum, proximal colon and distal colon while there was also a higher, albeit not statistically significant, expression in the skeletal muscle, heart and lung. Interestingly, the enrichment was observed in the tissues endowed with functional roles in $\mathrm{Ca}^{2+}$ and lipid transport. In line with our results showing disparate enrichment between organs, various reports have emphasized that various TG mouse models equipped, genetically manipulated in different genes expressed variable amounts of mRNA in peripheral tissues [40]. More specifically, the pCAG promoter in the Rosa26 locus suffers from mosaic transgene expression among organs [41] and the responder gene expression was moderate and highly variable between and within different tissues [42]. 
We have evaluated the effect of transgenesis on Sar1b protein expression in the the liver and jejunum, the two key organs involved in lipid transport and lipoprotein assembly. Fig. $5 \mathrm{~A}$ shows that Sar1b in these two organs is elevated in TG compared to WT mice. In fact, we found $446 \%(\mathrm{P}<0.004)$ and $388 \%(\mathrm{P}<0.022)$ increases in Sar1b expression in the liver and jejunum, respectively. This corresponds to the elevation in gene expression in these organs presented in Fig. 4. Compared to WT animals, transgenesis led to elevated gene expression $(459 \%, \mathrm{P}<0.0015)$ in the liver and in the jejunum (90\%), although the differences in the latter were not statistically significant. Using standard RT-PCR method, we have also compared the endogenous and exogenous Sar1b gene expression in mice. Fig. 5B reveals that the exogenous gene expression in transgenic animals represents approximately $70 \%$ of the total expression in the liver and in jejunum.

A limit of the present work is that it was performed in mice, which does not necessarily reflect the expression profile in humans. However, previous investigation has shown that the presence of Sar1b in the digestive tract is consistent in different species: it was found in the human duodenum [15], in the human Caco-2/15 cell model [25], in the small intestine of hamsters [36] and in rat enterocytes [43]. Further studies are needed to evaluate the distribution and expression profile of Sar1 $\mathrm{b}$ in the human digestive tract and in other tissues.

\section{Conclusions}

In conclusion, in our mouse model Sar1b was not regulated by insulin resistance or by high-fat content. However, the results obtained from tissue distribution pattern and regulation by transgenesis support the importance of Sar1b in organs involved in lipid transport such as the liver, jejunum, ileum and colon, which highlight its crucial role in organs transporting lipids. Interestingly our findings also support a significant role for Sar1b in organs necessitating major $\mathrm{Ca}^{2+}$ trafficking, namely the skeletal muscle and the heart.

\section{Acknowledgements}

This work was supported by grants from Canadian Institutes of Health Research (MOP 10584), the JA deSève Research Chair in nutrition (EL), the Canada Research Chair in Immune Mediated Gastrointestinal Disorders (ES), the Canadian Institutes of Health Research Fellowship Award and The Richard and Edith Strauss Postdoctoral Fellowships Award in Medicine, McGill University (VM). The authors thank Dr Randy W Schekman, Howard Hugues Medical Institute Reagents of the University of California, for providing SAR1a/b antibody.

\section{References}

1 Antonny B, Schekman R: ER export: public transportation by the COPII coach. Curr Opin Cell Biol 2001;13:438-443.

- 2 Barlowe C, Orci L, Yeung T, Hosobuchi M, Hamamoto S, Salama N, Rexach MF, Ravazzola M, Amherdt M, Schekman R: COPII: a membrane coat formed by Sec proteins that drive vesicle budding from the endoplasmic reticulum. Cell 1994;77:895-907.

3 Barlowe C: Signals for COPII-dependent export from the ER: what's the ticket out? Trends Cell Biol 2003;13:295-300.

4 Gillon AD, Latham CF, Miller EA: Vesicle-mediated ER export of proteins and lipids. Biochim Biophys Acta 2012;1821:1040-1049.

5 Kirchhausen T: Three ways to make a vesicle. Nat Rev Mol Cell Biol 2000;1:187-198. 
6 Barlowe C, Schekman R: SEC12 encodes a guanine-nucleotide-exchange factor essential for transport vesicle budding from the ER. Nature 1993;365:347-349.

7 Futai E, Hamamoto S, Orci L, Schekman R: GTP/GDP exchange by Sec12p enables COPII vesicle bud formation on synthetic liposomes. EMBO J 2004;23:4146-4155.

8 Bi X, Corpina RA, Goldberg J: Structure of the Sec23/24-Sar1 pre-budding complex of the COPII vesicle coat. Nature 2002;419:271-277.

-9 Matsuoka K, Orci L, Amherdt M, Bednarek SY, Hamamoto S, Schekman R, Yeung T: COPII-coated vesicle formation reconstituted with purified coat proteins and chemically defined liposomes. Cell 1998;93:263275.

10 Aridor M, Traub LM: Cargo selection in vesicular transport: the making and breaking of a coat. Traffic 2002;3:537-546.

11 Jones B, Jones EL, Bonney SA, Patel HN, Mensenkamp AR, Eichenbaum-Voline S, Rudling M, Myrdal U, Annesi G, Naik S, Meadows N, Quattrone A, Islam SA, Naoumova RP, Angelin B, Infante R, Levy E, Roy CC, Freemont PS, Scott J, Shoulders CC: Mutations in a Sar1 GTPase of COPII vesicles are associated with lipid absorption disorders. Nat Genet 2003;34:29-31.

12 Peretti N, Sassolas A, Roy CC, Deslandres C, Charcosset M, Castagnetti J, Pugnet-Chardon L, Moulin P, Labarge S, Bouthillier L, Lachaux A, Levy E: Guidelines for the diagnosis and management of chylomicron retention disease based on a review of the literature and the experience of two centers. Orphanet J Rare Dis 2010;5:24.

13 Charcosset M, Sassolas A, Peretti N, Roy CC, Deslandres C, Sinnett D, Levy E, Lachaux A: Anderson or chylomicron retention disease: molecular impact of five mutations in the SAR1B gene on the structure and the functionality of Sar1b protein. Mol Genet Metab 2008;93:74-84.

14 Peretti N, Roy CC, Sassolas A, Deslandres C, Drouin E, Rasquin A, Seidman E, Brochu P, Vohl MC, Labarge S, Bouvier R, Samson-Bouma ME, Charcosset M, Lachaux A, Levy E: Chylomicron retention disease: a long term study of two cohorts. Mol Genet Metab 2009;97:136-142.

15 Georges A, Bonneau J, Bonnefont-Rousselot D, Champigneulle J, Rabes JP, Abifadel M, Aparicio T, Guenedet JC, Bruckert E, Boileau C, Morali A, Varret M, Aggerbeck LP, Samson-Bouma ME: Molecular analysis and intestinal expression of SAR1 genes and proteins in Anderson's disease (Chylomicron retention disease). Orphanet J Rare Dis 2011;6:1.

-16 Silvain M, Bligny D, Aparicio T, Laforet P, Grodet A, Peretti N, Menard D, Djouadi F, Jardel C, Begue JM, Walker F, Schmitz J, Lachaux A, Aggerbeck LP, Samson-Bouma ME: Anderson's disease (chylomicron retention disease): a new mutation in the SARA2 gene associated with muscular and cardiac abnormalities. Clin Genet 2008;74:546-552.

17 Annesi G, Aguglia U, Tarantino P, Annesi F, De Marco EV, Civitelli D, Torroni A, Quattrone A: SIL1 and SARA2 mutations in Marinesco-Sjogren and chylomicron retention diseases. Clin Genet 2007;71:288-289.

18 Treepongkaruna S, Chongviriyaphan N, Suthutvoravut U, Charoenpipop D, Choubtum L, Wattanasirichaigoon D: Novel missense mutations of SAR1B gene in an infant with chylomicron retention disease. J Pediatr Gastroenterol Nutr 2009;48:370-373.

$\checkmark 19$ Cefalu AB, Calvo PL, Noto D, Baldi M, Valenti V, Lerro P, Tramuto F, Lezo A, Morra I, Cenacchi G, Barbera C, Averna MR: Variable phenotypic expression of chylomicron retention disease in a kindred carrying a mutation of the Sara2 gene. Metabolism 2010;59:463-467.

20 Levy E, Marcel Y, Deckelbaum RJ, Milne R, Lepage G, Seidman E, Bendayan M, Roy CC: Intestinal apoB synthesis, lipids, and lipoproteins in chylomicron retention disease. J Lipid Res 1987;28:1263-1274.

21 Levy E, Chouraqui JP, Roy CC: Steatorrhea and disorders of chylomicron synthesis and secretion. Pediatr Clin North Am 1988;35:53-67.

22 Roy CC, Levy E, Green PH, Sniderman A, Letarte J, Buts JP, Orquin J, Brochu P, Weber AM, Morin CL: Malabsorption, hypocholesterolemia, and fat-filled enterocytes with increased intestinal apoprotein B. Chylomicron retention disease. Gastroenterology 1987;92:390-399.

23 Strich D, Goldstein R, Phillips A, Shemer R, Goldberg Y, Razin A, Freier S: Anderson's disease: no linkage to the apo B locus. J Pediatr Gastroenterol Nutr 1993;16:257-264.

24 Gusarova V, Caplan AJ, Brodsky JL, Fisher EA: Apoprotein B degradation is promoted by the molecular chaperones hsp90 and hsp70. J Biol Chem 2001;276:24891-24900. 
25 Levy E, Harmel E, Laville M, Sanchez R, Emonnot L, Sinnett D, Ziv E, Delvin E, Couture P, Marcil V, Sane AT: Expression of Sar1b enhances chylomicron assembly and key components of the coat protein complex II system driving vesicle budding. Arterioscler Thromb Vasc Biol 2011;31:2692-2699.

-26 Kisseberth WC, Brettingen NT, Lohse JK, Sandgren EP: Ubiquitous expression of marker transgenes in mice and rats. Dev Biol 1999;214:128-138.

27 Levy E, Menard D, Suc I, Delvin E, Marcil V, Brissette L, Thibault L, Bendayan M: Ontogeny, immunolocalisation, distribution and function of SR-BI in the human intestine. J Cell Sci 2004;117:327-337.

-28 Livak KJ, Schmittgen TD: Analysis of relative gene expression data using real-time quantitative PCR and the 2(-Delta Delta C(T)) Method. Methods 2001;25:402-408.

-29 Levy E, Spahis S, Garofalo C, Marcil V, Montoudis A, Sinnet D, Sanchez R, Peretti N, Beaulieu JF, Sane A: Sar1b transgenic male mice are more susceptible to high-fat diet-induced obesity, insulin insensitivity and intestinal chylomicron overproduction. J Nutr Biochem 2014.

- 30 Fromme JC, Ravazzola M, Hamamoto S, Al-Balwi M, Eyaid W, Boyadjiev SA, Cosson P, Schekman R, Orci L: The genetic basis of a craniofacial disease provides insight into COPII coat assembly. Dev Cell 2007;13:623634.

- 31 Nori A, Bortoloso E, Frasson F, Valle G, Volpe P: Vesicle budding from endoplasmic reticulum is involved in calsequestrin routing to sarcoplasmic reticulum of skeletal muscles. Biochem J 2004;379:505-512.

32 Zhuang X, Chowdhury S, Northup JK, Ray K: Sar1-dependent trafficking of the human calcium receptor to the cell surface. Biochem Biophys Res Commun 2010;396:874-880.

33 Yamasaki A, Tani K, Yamamoto A, Kitamura N, Komada M: The $\mathrm{Ca}^{2+}$-binding protein ALG-2 is recruited to endoplasmic reticulum exit sites by Sec31A and stabilizes the localization of Sec31A. Mol Biol Cell 2006;17:4876-4887.

- 34 Higazi DR, Fearnley CJ, Drawnel FM, Talasila A, Corps EM, Ritter O, McDonald F, Mikoshiba K, Bootman MD, Roderick HL: Endothelin-1-stimulated InsP3-induced Ca2+ release is a nexus for hypertrophic signaling in cardiac myocytes. Mol Cell 2009;33:472-482.

-35 Guo A, Cala SE, Song LS: Calsequestrin accumulation in rough endoplasmic reticulum promotes perinuclear $\mathrm{Ca}^{2+}$ release. J Biol Chem 2012;287:16670-16680.

-36 Wong DM, Webb JP, Malinowski PM, Xu E, Macri J, Adeli K: Proteomic profiling of intestinal prechylomicron transport vesicle (PCTV)-associated proteins in an animal model of insulin resistance ( 94 char). J Proteomics 2010;73:1291-1305.

37 Matsuoka K, Morimitsu Y, Uchida K, Schekman R: Coat assembly directs V-SNARE concentration into synthetic COPII vesicles. Mol Cell 1998;2:703-708.

-38 Runz H, Miura K, Weiss M, Pepperkok R: Sterols regulate ER-export dynamics of secretory cargo protein ts-045-G. EMBO J 2006;25:2953-2965.

-39 Ridsdale A, Denis M, Gougeon PY, Ngsee JK, Presley JF, Zha X: Cholesterol is required for efficient endoplasmic reticulum-to-Golgi transport of secretory membrane proteins. Mol Biol Cell 2006;17:15931605.

40 Ma X, Robin C, Ottersbach K, Dzierzak E: The Ly-6A (Sca-1) GFP transgene is expressed in all adult mouse hematopoietic stem cells. Stem Cells 2002;20:514-521.

-41 Nyabi O, Naessens M, Haigh K, Gembarska A, Goossens S, Maetens M, De CS, Drogat B, Haenebalcke L, Bartunkova S, De V, I, De CB, Karimi M, Berx G, Nagy A, Hilson P, Marine JC, Haigh JJ: Efficient mouse transgenesis using Gateway-compatible ROSA26 locus targeting vectors and F1 hybrid ES cells. Nucleic Acids Res 2009;37:e55.

42 Wortge S, Eshkind L, Cabezas-Wallscheid N, Lakaye B, Kim J, Heck R, Abassi Y, Diken M, Sprengel R, Bockamp E: Tetracycline-controlled transgene activation using the ROSA26-iM2-GFP knock-in mouse strain permits GFP monitoring of DOX-regulated transgene-expression. BMC Dev Biol 2010;10:95.

43 Siddiqi SA, Mahan J, Siddiqi S, Gorelick FS, Mansbach CM: Vesicle-associated membrane protein 7 is expressed in intestinal ER. J Cell Sci 2006;119:943-950. 